\title{
Novel core in cup (In-lay) tablets of lamotrigine for mucoadhesive drug delivery system
}

\author{
K. Srinija and *P.K. Lakshmi \\ Department of Pharmaceutics, G Pulla Reddy College of Pharmacy, Mehdipatnam, Hyderabad, Telangana, India
}

\begin{abstract}
Lamotrigine a BCS class II drug used in treatment of epilepsy has several disadvantages when taken orally (first pass metabolism and increased $C_{\max }$ ). The aim of the study is to design core in cup (In lay) buccoadhesive tablets which aims for controlled, unidirectional release, increased patient compliance and decreased side effects. The present study involves the preparation of core in cup tablets containing release retarding polymers like sodium alginate, xanthan gum and HPMC E 15LV in core and HPMC K 15M in cup for mucoadhesion. L9 orthogonal array Taguchi design was constructed for the study. The dependent variable studied for L9 orthogonal array Taguchi runs include \% drug release from which the formulation with highest S/N ratio was optimized. All the runs were evaluated for physical parameters, drug release, mucoadhesive studies and assay. L1, L2, L4 and L8 formulations showed controlled release for up-to 8 hours with good assay values. The model dependent kinetics showed zero order kinetics with super case II transport and Hixson Crowell mechanism which indicates unidirectional drug release.
\end{abstract}

Abbreviations: \%, percentage; BCS, biopharmaceutical classification system; $\mathrm{h}$, hours; ${ }^{\circ} \mathrm{C}$, degrees Celsius; $\mathrm{Mg}$, milligrams; $\mathrm{MDT}$, mean dissolution time; rpm, revolution per minute; \#, sieve number; USP, United States pharmacopoeia; UV, ultra violet; $r^{2}$, correlation coefficient; $n$, release exponent (power law Korsmeyer Peppas equation), $\mathrm{S} / \mathrm{N}$, signal to noise.

Key Words: Core in cup (In-lay) tablets, Lamotrigine, L9 orthogonal array Taguchi design, zero order kinetics, unidirectional release.

\section{INTRODUCTION}

The oral cavity is the attractive site for the delivery of drugs due to high patient compliance, ease in administration, direct access to systemic circulation, avoids first pass metabolism and also degradation in GIT. Oral cavity delivers the drug through sublingually from the floor of the mouth, locally for local delivery into oral cavity and buccal delivery through buccal mucosa. Buccal drug delivery system is only responsible for administration of retentive dosage form (Mujoriya et al., 2011). It is advantageous over transdermal delivery due to increased permeation, i.e., 4-4000 times greater than transdermal delivery (Patel et al., 2011).

Lamotrigine, an antiepileptic drug (AED) of the phenyltriazine class, had several disadvantageous when given orally. Immediate release formulations of lamotrigine lead to high first pass metabolism (Mashru et al., 2005) cyclical observations of peak plasma concentration, severe side-effects, rashes due to rapid increase in blood plasma levels after each dosing (Werz, 2008), increased glucoronidation during menopause and oral contraceptive therapy due to increased cytochrome p450 enzyme (Gaffield et al., 2011), changes in lamotrigine clearance during pregnancy (Harden, 2002). To ameliorate the drawbacks associated with immediate release formulations, lamotrigine is formulated into buccal mucoadhesive controlled release dosage form.

Solubility of lamotrigine is $\mathrm{pH}$ dependent. Studies revealed that as the $\mathrm{pH}$ increases the solubility of drug gets decreased but with buccal $\mathrm{pH}$ (6.8) though the solubility of lamotrigine is low the partition coefficient

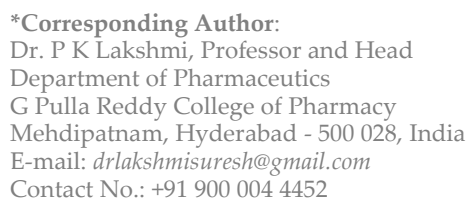

and permeability coefficient of drug made it possible for the transport of drug through buccal mucosa. This is due to availability of drug in unionized form $(98 \%)$ due to which the drug transport occurs through transcellular route, which forms basis for the buccal drug delivery (Patel et al., 2011).

The core in cup (In-lay) buccal tablets offers several advantages like availability of active ingredient for modified release, ability to release drugs at a zero-order rate and maintenance of plasma concentration with in therapeutic window (Modi et al., 2013).

The present study involves the preparation of core in cup (In-lay) buccoadhesive tablets of lamotrigine. The core and cup are different from each other in which the core consists of lamotrigine with other control release polymers like sodium alginate, xanthan gum and HPMC E $15 \mathrm{LV}$ and cup consists of mucoadhesive polymer (HPMC K 15M).

Buccal route is one such alternative and buccal route has not been explored for the administration of this drug. The drug is available in the market as conventional tablet and the buccal permeation forms the basis for the drug to formulate as buccal tablet and the core in cup tablets were responsible for the controlled release and maintenance of drug concentration in the plasma.

L9 orthogonal array Taguchi design was constructed to minimizes the experimental trials. All the runs were evaluated for the in vitro drug release, swelling index, surface $\mathrm{pH}$, assay, MDT, ex-vivo mucoadhesion strength and time. The dependent variable studied for L9 orthogonal array Taguchi runs include \% drug release.

\section{MATERIALS AND METHODS}

Lamotrigine, eudragit L100, eudragit S 100, are obtained from Evonik Roehm Pharma polymers. Sodium alginate, Xanthan gum, HPMC E 15LV and HPMC K 15M are obtained from Yarrow Chem. products, Mumbai. Talc, magnesium stearate and lactose monohydrate are 
obtained from SD fine chemicals. All chemical reagents used were of analytical grade. Goat buccal mucosa was obtained from a slaughter house.

Preparation of $6.8 \mathrm{pH}$ Mcilvaine buffer: $772.5 \mathrm{ml}$ of $0.2 \mathrm{M}$ disodium hydrogen phosphate solution was transferred into a $1000 \mathrm{ml}$ volumetric flask and volume was made up to $1000 \mathrm{ml}$ with $0.1 \mathrm{M}$ citric acid solution.

Preparation of $0.2 \mathrm{M}$ disodium hydrogen phosphate solution: $35.5 \mathrm{gm}$ of disodium hydrogen phosphate was taken into $1000 \mathrm{ml}$ volumetric flask and dissolved in small quantity of distilled water. Finally, volume was made up to $1000 \mathrm{ml}$ with distilled water.

Preparation of $0.1 \mathrm{M}$ citric acid: $20.01 \mathrm{gm}$ citric acid was taken into $1000 \mathrm{ml}$ volumetric flask and dissolved in small quantity of distilled water. Finally, volume was made up to $1000 \mathrm{ml}$ with distilled water.

\section{Pre-compression flow properties and compressibility of buccal core in cup tablets}

All the pre-compression properties were determined independently for core tablet as well as for the coat/cup. The bulk and tapped densities were determined with USP tap density apparatus (Electrolab) from which Hausner's ratio and compressibility index (\% Carrs's index) were calculated. Fixed funnel method was used for the angle of repose determination.

\section{Preparation of core in cup buccoadhesive tablets}

The core in cup buccal tablets was prepared by direct compression method. All the ingredients for the core tablet were screened through \#60. Lamotrigine was mixed with polymers, talc and lactose monohydrate as diluent for $10 \mathrm{~min}$. Then blends were lubricated with magnesium stearate for $3-5 \mathrm{~min}$. The core mixture is compressed using 10 station rotary tablet compression machine by $6 \mathrm{~mm}$ punches. Then upper punch was raised and the precompressed core tablet was removed from $6 \mathrm{~mm}$ punch and placed onto $8 \mathrm{~mm}$ punch then turret was allowed to move to an extent and the mucoadhesive layer (HPMC K $15 \mathrm{M})$ was added to the die containing core tablet and compressed again to attain core in cup buccal tablets.

\section{Experimental design}

The effect of different parameters on the mean and variance of the process performance was investigated by Taguchi experimental design (Sharma et al., 2005; Maghsoodloo and Ozdemir, 2004). In this design, orthogonal arrays arrange the affecting parameters and their levels in the way, most likely to affect the process. Unlike factorial design, in which all possible combinations are tested, Taguchi employs a minimal number of trials by testing pairs of combinations. This saves both time and resources. The optimal parameters obtained from these trials are not sensitive to environmental changes and other noise factors. "Minitab 15" was the software employed to carry out Taguchi experimental design.

\section{Optimization of formulation}

In the present study, the following three process parameters were selected: type of controlled release polymer, drug: concentration of polymer and concentration of binder. Each of these parameters was at three different levels, as stated in table 1 . Three parameters, at three levels each, would give 27 experiments in full factorial design but only nine experimental runs by $3 \times 3$ designs using L9 orthogonal array Taguchi design, as shown in table 2. The sequence of the experimental runs was randomized to prevent any bias.

Total weight of tablet is $150 \mathrm{mg}$ and core tablet weighs about $75 \mathrm{mg}$ which consists of drug (25mg), magnesium stearate $(2 \%)$, talc $(2 \%)$, lactose monohydrate as diluent (qs) in constant along with the polymer and binder as mentioned in table 2. The outer coat/cup consists of $75 \mathrm{mg}$ of HPMC K 15M.

\section{Evaluation of core in cup (In-lay) buccal tablets In-process tests}

Weight variation, hardness and friability tests were carried out for all the formulations (Raju et al., 2012). Tablets were evaluated for the weight variation using electronic balance. Thickness and hardness were measured by screw gauge and Monsanto hardness tester and friability by Roche friabilator.

\section{Assay}

Ten tablets were taken and grounded into fine powder. Powder equivalent to $25 \mathrm{mg}$ of drug was weighed and transferred to $50 \mathrm{ml}$ volumetric flask containing $25 \mathrm{ml}$ of methanol and finally made the volume to $50 \mathrm{ml}$ with methanol. The volumetric flask was sonicated for 15 minutes. To $50 \mathrm{ml}$ of volumetric flask add $2 \mathrm{ml}$ of above solution, add $25 \mathrm{ml} 6.8 \mathrm{pH}$ Mcilvaine buffer and make up the volume to $50 \mathrm{ml}$ with buffer (Raju et al., 2012; Patel et al., 2012) and checked for the absorbance at $304.5 \mathrm{~nm}$ in UV spectrophotometer.

\section{In Vitro drug Release}

USP type I apparatus was used to carry out dissolution using $500 \mathrm{ml}$ Mcilvaine buffer for 8 hours, during which the aliquots $(5 \mathrm{ml})$ were withdrawn for every one hour and replaced with fresh media (Raju et al., 2012; Patel et al., 2012). The absorbance was checked at $304.5 \mathrm{~nm}$ in UV spectrophotometer (Chemito Instruments Pvt. Ltd., Mumbai, India) and the concentration of drug released was calculated using calibration curve.

Table 1: Selection of independent variables for L9 orthogonal array Taguchi design.

\begin{tabular}{cccc}
\hline $\begin{array}{c}\text { Factors (independent } \\
\text { variables) }\end{array}$ & \multicolumn{3}{c}{ Levels } \\
\cline { 2 - 4 } & Low & Medium & High \\
\hline $\begin{array}{c}\text { Factor A: Type of controlled } \\
\text { release polymer }\end{array}$ & $\begin{array}{c}\text { Sodium } \\
\text { alginate }\end{array}$ & $\begin{array}{c}\text { Xanthan } \\
\text { gum }\end{array}$ & $\begin{array}{c}\text { HPMC E } \\
15 \mathrm{LV}\end{array}$ \\
$\begin{array}{c}\text { Factor B: Drug: Concentration } \\
\text { of polymer (\%) }\end{array}$ & $1: 0.5$ & $1: 0.75$ & $1: 1$ \\
$\begin{array}{c}\text { Factor C: Concentration of } \\
\text { binder (\%) }\end{array}$ & 0 & 3 & 5 \\
\hline
\end{tabular}

Table 2: Various trials to be carried out according to L9 orthogonal array.

\begin{tabular}{cccc}
\hline Run & $\begin{array}{c}\text { Factor A (Type of } \\
\text { control release } \\
\text { polymer) }\end{array}$ & $\begin{array}{c}\text { Factor B (drug: } \\
\text { concentration of } \\
\text { polymer) }\end{array}$ & $\begin{array}{c}\text { Factor C } \\
\text { (\% of binder) }\end{array}$ \\
\hline 1 & Sodium alginate & $1: 0.50$ & 0 \\
2 & Sodium alginate & $1: 0.75$ & 3 \\
3 & Sodium alginate & $1: 1$ & 5 \\
4 & Xanthan gum & $1: 0.50$ & 3 \\
5 & Xanthan gum & $1: 0.75$ & 5 \\
6 & Xanthan gum & $1: 1$ & 0 \\
7 & HPMC E 15 LV & $1: 0.50$ & 5 \\
8 & HPMC E 15 LV & $1: 0.75$ & 0 \\
9 & HPMC E 15 LV & $1: 1$ & 3 \\
\hline
\end{tabular}




\section{Swelling Study}

Buccal tablets were weighed individually $\left(\mathrm{W}_{1}\right)$ and placed separately in $2 \%$ agar gel plates with core facing the gel surface and incubated at $37 \pm 1^{\circ} \mathrm{C}$. After 8 hours the tablet was removed from the Petri dish, and excess surface water was removed carefully with filter paper. The swollen tablet was then reweighed $\left(\mathrm{W}_{2}\right)$ and the swelling index (SI) were calculated using the formula (Patel et al., 2012).

$$
\% S I=\frac{W 2-W 1}{W 1} \times 100
$$

\section{Ex-vivo mucoadhesion time}

The tablet was placed over excised goat mucosa which is secured on glass slide and pressed for $30 \mathrm{sec}$ and was immersed in a basket of the dissolution apparatus containing about $750 \mathrm{ml}$ of $\mathrm{pH} 6.8$ Mcilvaine buffer, at $37^{\circ} \mathrm{C}$. The paddle of the dissolution apparatus was adjusted at a distance of $5 \mathrm{~cm}$ from the tablet and rotated at $25 \mathrm{rpm}$. The time for complete erosion or detachment from the mucosa was recorded (Raju et al., 2012; Patel et al., 2012).

\section{Ex-Vivo Mucoadhesive Strength}

A modified balance method was used to study the ex vivo mucoadhesive strength (Raju et al., 2012). Fresh goat buccal mucosa was obtained from a local slaughterhouse and used within 2 hours. The mucosal membrane was separated by removing underlying fat and loose tissues. The membrane was washed with distilled water and then with Mcilvaine buffer $\mathrm{pH} 6.8$ solutions at $37^{\circ} \mathrm{C}$. A piece of buccal mucosa was tied to the cork and was fitted into a glass beaker (filled with Mcilvaine buffer $\mathrm{pH}$ 6.8, at $37 \pm 1^{\circ} \mathrm{C}$ ) so that it just touches the mucosal surface. The buccal tablet was placed to the lower side of a glass stopper with cyanoacrylate adhesive. The two sides of the balance were made equal before the study, by keeping a 5$\mathrm{g}$ weight on the right-hand pan. A weight of $5 \mathrm{~g}$ was removed from the right-hand pan, which lowered the pan along with the tablet over the mucosa (Raju et al., 2012; Patel et al., 2012). The balance was kept in this position for 5 minutes. Different weight was put slowly to the righthand pan until the tablet detached from the mucosal surface. This detachment force gave the mucoadhesive strength of the buccal tablet in grams.

\section{RESULTS AND DISCUSSION}

\section{Formulation of buccal core in cup tables}

The $\mathrm{S} / \mathrm{N}$ ratio for larger-the-better characteristic was chosen for \% drug release in $6.8 \mathrm{pH}$ Mcilvaine buffer. The $\mathrm{S} / \mathrm{N}$ ratio for the response is given in table 3 . The mean of these $\mathrm{S} / \mathrm{N}$ ratios at each level of process variable is summarized in table 4 and figure 1 . The ranks obtained for each factor determine its effect on the drug release pattern. Table 3 shows that the ratio between drug and concentration of polymer plays primary role in drug release from the tablet. The characteristic for optimization of tablets is the largest $\mathrm{S} / \mathrm{N}$ ratio. Based on this, as depicted in table 3 , it can be concluded that the tablets would be optimized for \% drug release when the processing conditions are $\mathrm{A} 1 \mathrm{~B} 2 \mathrm{C} 2$ which represents sodium alginate as the controlled release polymer in 0.75:1 ratios with drug and PVP K 30 in $3 \%$ as binder. Similarly, from table 4 the highest value was observed for experiment run 2, i.e., L2 formulation. Hence L2 formulation was optimized.
Table 3: Response table for $\mathrm{S} / \mathrm{N}$ ratio.

\begin{tabular}{cccc}
\hline Level & A & B & C \\
\hline 1 & 38.07 & 37.51 & 36.39 \\
2 & 36.14 & 38.01 & 37.51 \\
3 & 36.61 & 35.3 & 36.94 \\
Delta & 1.93 & 2.71 & 1.12 \\
Rank & 2 & 1 & 3 \\
\hline
\end{tabular}

Table 4: Signal to noise ratio of response for all experimental runs.

\begin{tabular}{cc}
\hline Experimental run & $\begin{array}{c}\text { S/N ratio of response } \\
\text { (\% drug release) }\end{array}$ \\
\hline 1 & 38.0815 \\
2 & 39.7 \\
3 & 36.4248 \\
4 & 37.2759 \\
5 & 37.2094 \\
6 & 33.949 \\
7 & 37.1764 \\
8 & 37.1292 \\
9 & 35.539 \\
\hline
\end{tabular}

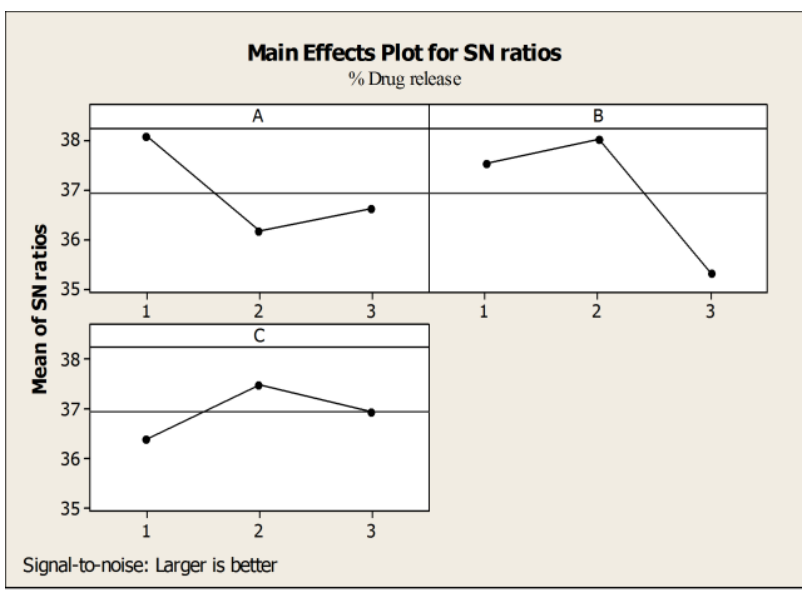

Figure 1: Main effects plot for $\mathrm{S} / \mathrm{N}$ ratio of $\%$ drug release.

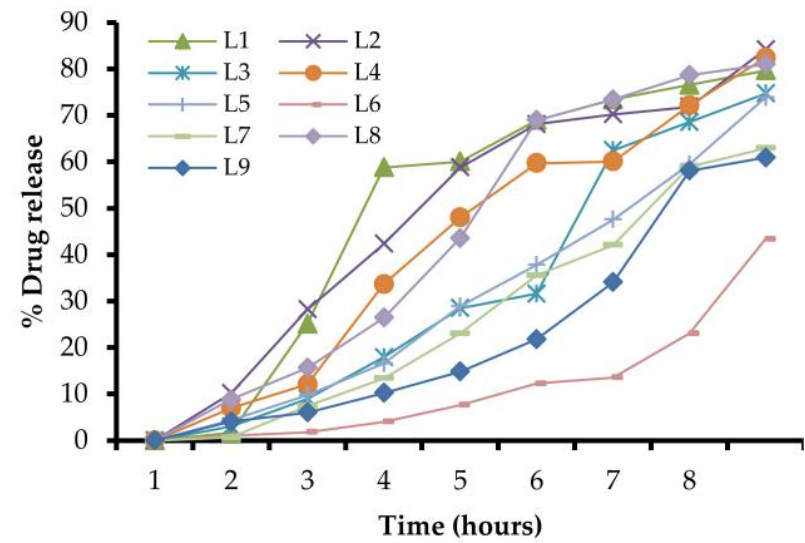

Figure 2: Comparative dissolution profiles of L9 orthogonal array experimental runs. 
Table 5: Model dependent kinetic analysis of the dissolution profiles of L9 orthogonal array Taguchi runs.

\begin{tabular}{|c|c|c|c|c|c|c|c|c|}
\hline \multirow[t]{2}{*}{ Runs } & \multirow{2}{*}{$\begin{array}{c}\text { Zero order } \\
\text { release model } \\
\text { parameters }\end{array}$} & \multirow{2}{*}{$\begin{array}{c}\begin{array}{c}\text { First order } \\
\text { release model } \\
\text { parameters }\end{array} \\
\mathbf{r}^{2} \\
\end{array}$} & \multirow{2}{*}{$\begin{array}{c}\begin{array}{c}\text { Higuchi release } \\
\text { model } \\
\text { parameters }\end{array} \\
\mathbf{r}^{2}\end{array}$} & \multicolumn{3}{|c|}{$\begin{array}{c}\text { Korsmeyer-Peppas release model } \\
\text { parameters }\end{array}$} & \multirow[t]{2}{*}{$\begin{array}{c}\text { Release } \\
\text { mechanism }\end{array}$} & \multirow{2}{*}{$\begin{array}{c}\begin{array}{c}\text { Hixson Crowell } \\
\text { release model } \\
\text { parameter }\end{array} \\
\mathbf{r}^{2}\end{array}$} \\
\hline & & & & $\mathbf{r}^{2}$ & $K_{k p}$ & $\mathbf{n}$ & & \\
\hline L1 & 0.82 & 0.55 & 0.91 & 0.8 & 0.613 & 1.68 & super case II & 0.9 \\
\hline L2 & 0.92 & 0.76 & 0.97 & 0.95 & 0.98 & 1.1 & super case II & 0.96 \\
\hline L3 & 0.95 & 0.9 & 0.91 & 0.98 & 0.483 & 1.58 & super case II & 0.93 \\
\hline $\mathrm{L} 4$ & 0.96 & 0.84 & 0.97 & 0.96 & 0.83 & 1.26 & super case II & 0.97 \\
\hline L5 & 0.98 & 0.93 & 0.94 & 0.99 & 0.61 & 1.37 & super case II & 0.97 \\
\hline L6 & 0.81 & 0.97 & 0.71 & 0.95 & 0.13 & 1.75 & super case II & 0.95 \\
\hline L7 & 0.98 & 0.92 & 0.94 & 0.99 & 0.41 & 1.57 & super case II & 0.911 \\
\hline L8 & 0.94 & 0.97 & 0.95 & 0.97 & 0.911 & 1.18 & super case II & 0.98 \\
\hline L9 & 0.9 & 0.98 & 0.82 & 0.93 & 0.456 & 1.37 & super case II & 0.86 \\
\hline
\end{tabular}

Tablet physical properties and characterization

The major excipients selected for the core tablet were the drug and control release polymer (sodium alginate, xanthan gum and HPMC E 15LV). The outer coat/cup predominantly comprised of HPMC K 15M. The precompression flow properties were studied separately for both core and coat/cup. Flow properties were further improved by the addition of lubricant, magnesium stearate which was added prior to tableting. Angle of repose values of the core ranged between $15^{\circ}$ and $34^{\circ}$ while that of the coat/cup was $32^{\circ}$. The compressibility index values of the formulation batches ranged between $14 \%$ and $21 \%$ for both core and coat/cup indicating the suitability of the powders for dry granulation. Hausner's ratio ranged between 1.16 and 1.27 for both core and coat/cup.

The addition of different polymers did not affect the tablet physical characteristics. All the tablet formulations presented hardness in the range $4-6 \mathrm{~kg} / \mathrm{cm}^{2}$. The percent friability values reported for the tablet formulations were very low $(<0.55 \%)$ with no measurable differences among the between batch results. The thickness ranged between $1.70 \pm 0.02 \mathrm{~mm}$ and $1.82 \pm 0.02 \mathrm{~mm}$ while the weight of different batch formulations varied between $150 \pm 0.78 \mathrm{mg}$ and $150 \pm 0.94 \mathrm{mg}$.

\section{Assay}

The drug content of each batch of all the formulations (L1L9) was evaluated as per the standard protocol. The results indicate that the percentage of drug content was found to be 90.41 to $96.5 \%$.

\section{In-vitro drug release profile}

Formulations containing sodium alginate (F1-F3) showed drug release as $81.65 \%, 84.19 \%$ and $74.7 \%$, respectively. The formulation with 1: 0.75 ratios of drug: polymer and PVP K 30 of 3\% showed increased drug release in 8 hours.

Formulations containing xanthan gum (F4-F6) showed decreased drug release with increase in the concentration of the polymer. The initial burst release was seen with xanthan gum because it can hydrate rapidly even in cold water. It is highly swellable and showed sustained release (Mughal et al., 2011; Singh et al., 2011).

Xanthan gum provides time-independent release kinetics and establishes constant drug plasma levels as observed during in vivo drug release behaviour (Singh et al., 2011).

Formulations containing HPMC E 15LV with PVP K 30 (F7, F8 and F9) showed to have drug release as 62.93, 81.01 and $60.93 \%$, respectively. The results concluded that the drug release was influenced by PVP K 30 in which the 0\% PVP K 30 showed increased drug release, i.e., $81.01 \%$
(F8) when compared to F7 and F9 formulations with PVP $\mathrm{K} 30$ of $3 \%$ and $5 \%$, respectively. The decreased drug release is due to increased retarding efficiency of HPMC E 15LV and PVP K 30 in combination, i.e., synergistic effect was observed. It has been reported that HPMC with low viscosity grades also shows maximum release retarding efficiency in tablets containing 20-50\% (Mughal et al., 2011).

\section{Swelling index}

The swelling index studies were conducted for all the nine formulations using $2 \%$ agar gel. All the tablets were hydrated for 8 hours and \% SI was calculated. The highest swelling index $(70.39 \%$ for 8 hours) was seen with HPMC $\mathrm{E} 15 \mathrm{LV}$ and PVP $\mathrm{K} 30$ in $5 \%$. The reason for increased swelling index of HPMC E 15LV is due to high degree of erosion and low viscosity which makes the tablet to swell (Mughal et al., 2011; Singh et al., 2011).

\section{Ex-vivo mucoadhesion time}

Ex-vivo mucoadhesion studies were carried out for the all L9 Taguchi runs. The formulations containing sodium alginate and xanthan gum showed promising results than formulations with HPMC E $15 \mathrm{LV}$. The mucoadhesion time for sodium alginate and xanthan gum are more than 15 hours and for that of HPMC E $15 \mathrm{LV}$, where it is only about 8 hours. The reason for the decreased contact time or mucoadhesion time is due to swelling nature of polymer which makes tablet unable to withstand in contact position for longer durations.

\section{Characterization of the optimal formulation}

The formulations were further subjected to a detailed characterization in terms of release kinetics. The study results are presented in table 5 .

Table 6: Evaluation parameters.

\begin{tabular}{cccc}
\hline Code & $\begin{array}{c}\text { \% Swelling } \\
\text { index }\end{array}$ & MDT (hours) & $\begin{array}{c}\text { Mucoadhesive } \\
\text { time (hours) }\end{array}$ \\
\hline F1 & 34.8 & 0.832 & $>15$ \\
F2 & 48.6 & 0.528 & $>15$ \\
F3 & 49.35 & 0.966 & $>15$ \\
F4 & 49.7 & 0.644 & $>15$ \\
F5 & 50 & 0.826 & $>15$ \\
F6 & 55.2 & 1.97 & $>15$ \\
F7 & 63.1 & 1.07 & $>8$ \\
F8 & 68.8 & 0.58 & $>8$ \\
F9 & 70.39 & 1 & $>8$ \\
\hline
\end{tabular}


Kinetic analysis of drug release profiles and model fitting The evaluation of the drug release profile kinetics of the entire L9 orthogonal array Taguchi experimental runs was based on the correlation coefficient $\left(\mathrm{r}^{2}\right)$ values. The results depicted that all the release profiles best fitted into the zero order kinetic models (indicated by the highest $\mathrm{r}^{2}$ values) which signified that all the formulations by kinetics followed zero order which indicates controlled drug release except L6, L8 and L9 which showed first order kinetics.

\section{Release mechanism}

In order to understand the complex mechanism of drug release from the core in cup mucoadhesive tablet, the in vitro LM release data were studied using Korsmeyer Peppas release model. The release exponent $(n)$ values from the power law Peppas equation enlighten the release mechanism from the dosage form. The $n$ values thus obtained ranged from 1.1 to 1.75 which indicates super case II transport mechanism, i.e., drug release by both diffusion and relaxation of polymer chain (Bose et al., 2011; Kumar et al., 2012).

\section{Unidirectional drug release studies}

The regression coefficient was calculated from the Hixson Crowell equation and found that the $\mathrm{r}^{2}$ value of L2 was approximately equal to the $\mathrm{r}^{2}$ values of Higuchi kinetics which indicates unidirectional drug release.

\section{Mean dissolution time (MDT)}

Mean dissolution time (MDT) value is generally used to characterize the drug release rate from a dosage form and it indicates the drug release retarding efficiency of a polymer (Kumar et al., 2012). The results showed that the MDT values were found to be increased with increase in the concentration of the polymers. No effect was observed with the cup/coat of the tablet. The drug release retarding efficiency of polymers was in the order Xanthan gum $>$ HPMC E $15 \mathrm{LV}>$ sodium alginate.

\section{Ex vivo mucoadhesive strength}

The weight for which tablet got detached was 15.58 grams. The bioadhesive strength was found to be 15.58 grams and force of bioadhesion was found to be $0.152 \mathrm{~N}$ for L2 optimized formulation.

\section{Fourier transform infrared (FTIR) spectroscopy}

FTIR spectra of pure lamotrigine and the optimized tablet formulation were recorded with a FTIR spectrophotometer (FTIR-Shimadzu $8400 \mathrm{~S}$, Japan) from $4000-400 \mathrm{~cm}^{-1}$ using $\mathrm{KBr}$ press pellet method. The pellets were prepared using a mixture of lamotrigine, sodium alginate and $\mathrm{KBr}$ by applying a pressure of $100 \mathrm{~kg} / \mathrm{cm}^{2}$ for $2 \min$. The FTIR of optimized formulation showed no extra peaks with pure drug indicating no interaction between drug and the polymers therein.

\section{CONCLUSION}

The results signified that the in vitro development of core in cup mucoadhesive tablets with optimal mucoadhesion and ensured unidirectional controlled drug release profile for lamotrigine was feasible. From $\mathrm{S} / \mathrm{N}$ ratio it can be concluded that the concentration of the polymers plays an important role on the release of drug and formulation with sodium alginate: drug in 0.75:1 ratios and PVP K 30 in $3 \%$ was found to be optimized. The study of drug release kinetics and the mechanism indicated zero order drug release from the optimized formulation. Therefore, for a drug like lamotrigine, a BCS class II drug with $\mathrm{pH}$ dependent solubility and with high first pass metabolism the buccal drug delivery is feasible with controlled release up to 8 hours.

\section{REFERENCES}

Bose, S.C.P, Reddy, S.P., Valluru, R., Saritha, D., Kumar, P.T.M. (2011) Formulation and evaluation of sustained release floating tablets of diltiazem HCL using xanthan gum. RJPBCS. Volume 2, Issue 2, Pages 319-329.

Gaffield, M.E., Culwella, K.R, Lee, C.R. (2011). The use of hormonal contraception among women taking anticonvulsant therapy. Contraception. Volume 83, Issue 1, Pages 16-29. [DOI]

Harden, C.L (2002) Pregnancy Effects on Lamotrigine Levels. Epilepsy Curr. Volume 2, Issue 6, Pages 183. [DOI]

Kumar, S., Anup K Singh, S K Prajapati, Vijay K Singh (2012). Formulation and evaluation of once daily sustained release matrix tablet of aceclofenac using natural gums. Journal of Drug Delivery and Therapeutics. Volume 2, Issue 1, Pages 16-24.

Maghsoodloo, S., Ozdemir, G. (2004). Strengths and limitations of Taguchi's contributions to quality, manufacturing, and process engineering. J Manufact Syst. Volume 23, Pages 73-126. [DOI]

Mashru, R., Sutariya, V., Sankalia, M., Sankalia J. (2005). Transbuccal delivery of lamotrigine across porcine buccal mucosa: in vitro determination of routes of buccal transport. J Pharm Pharmaceut Sci. Volume 8, Issue 1, Pages 54-62. PMid:15946598

Modi, D., Amaliyar, P., Kalal, Y., et al. (2013). Novel Approach in Compressed-coated Tablet Dosage Form: Core-in-Cup (In Lay) Tablet with Geometrically Altered Drug Delivery Concept. British Biomedical Bulletin, Volume 1, Issue 2, Pages 90-102.

Mughal, M.A., Iqbal, Z., Neau, S.H. (2011). Guar Gum, Xanthan Gum, and HPMC Can Define Release Mechanisms and Sustain Release of Propranolol Hydrochloride. AAPS Pharm SciTech. Volume 12, Issue 1, Pages 77-87. [DOI]

Mujoriya, R., Dhamande, K., Wankhede, U.R., Angure, S. (2011) A Review on study of Buccal Drug Delivery System. Innovative Systems Design and Engineering. Volume 2, Issue 3, Pages 1-14.

Patel, A.A., Kanu Patel, Mukesh Patel, Natubhai Patel (2012). Formulation and In Vitro Evauation of Mucoadhesive Buccal Tablet of Venlafaxine Hydrochloride. Am. J. PharmTech Res. Volume 2, Issue 3, Pages 1081 1100.

Patel, K.V., Patel, N.D., et al. (2011). Buccal Bioadhesive Drug Delivery System: An Overview International Journal of Pharmaceutical and Biological Archives. Volume 2, Issue 2, Pages 600-609.

Raju, K.N., R. Ashok Kumar, B. Deepika, M. Chinna Eswaraiah, A Sambasiva Rao (2012). Formulation and in vitro evaluation of buccal tablets of captopril. Int. Res J Pharm. App Sci. Volume 2, Issue 2, Pages 21-43.

Sharma, P., Verma, A., Sidhu, R.K., Pandey, O.P. (2005). Process parameter selection for strontium ferrite sintered magnets using Taguchi L9 orthogonal design. J Mater Process Technol. Pages 147-151. [DOI]

Singh, A., Pramod Kumar Sharma, Rishabha Malviya. (2011) Release Behavior of Drugs from Various Natural Gums and Polymers. Polimery w Medycynie. Volume 41, Issue 4, Pages 73-80. PMid:22332328

Werz, M.A. (2008). Pharmacotherapeutics of epilepsy: use of lamotrigine and expectations for lamotrigine extended release. Therapeutics and Clinical Risk Management. Volume 4, Issue 5, Pages 1035-1046. 